\title{
The Thinking Language of Elementary School Teachers in the Arab Education System in Israel: Implications for Teacher Education
}

\author{
Jamal Abu-Hussain \\ Al-Qasemi Academy, Baqa-El-Gharbia, Israel \\ Email: Jamal ah@qsm.ac.il
}

Received 7 May 2015; accepted 26 June 2015; published 29 June 2015

Copyright (C) 2015 by author and Scientific Research Publishing Inc. This work is licensed under the Creative Commons Attribution International License (CC BY). http://creativecommons.org/licenses/by/4.0/

\section{(c) (i) Open Access}

\section{Abstract}

This pioneering study constitutes initial research on the topic of the thinking language of elementary school teachers in the Arab education system in Israel. The language of thinking can contribute significantly to every child and every classroom. However, written and spoken texts in the classroom at all levels use very few words referring to thinking. The current study attempts to bring the topic of thinking onto the agenda of the education system in general and the Arab education system in particular. This education system functions in a society characterized as developing and marked by a traditional culture. Thus, teaching in the Arab education system in Israel is still primarily a verbal activity. The objective of the study was to examine the language of thinking among teachers in the Arab elementary schools. It uses qualitative methodology through analysis of quantitative measures. The research tool involved the structured recording of the protocols of 38 lessons. The results of the study show that the thinking language of teachers in Arab elementary schools is sparse, ambiguous and inaccurate. Among the study's recommendations are to offer teachers continuing education courses on this topic, to train teachers at teacher training colleges in the language of thinking, and to allot special courses for teacher trainees. Such training programs should provide teacher trainees with experiential learning experiences to understand and develop their thinking, enabling them to use the language of thinking with their pupils.

\section{Keywords}

Thinking Language, Teachers, Elementary Schools, Teachers Education 


\section{Theoretical Background}

Leading educational systems have realized that the only way to improve outcomes and pupil achievement is to improve the standard of teaching itself [1].

Recent criticism of education has focused on the issue that education is aimed more at conveying facts than at developing thinking. More often, pupils receive knowledge without the qualities that make it clear, relevant, meaningful and important [2]. For example, pupils learn mathematics but they are not familiar with mathematical thinking [3].

In recent years, especially in view of pupils' low achievements on international tests, the development of thinking has become a central and important issue in the education system in Israel and the Arab education system in particular, as reflected in the pedagogical policy of the Ministry of Education in Israel. Educators have begun to understand that pupils need to be active in their learning and should be able to think on a high level. Programs to develop thinking began to appear in a significant number of schools [2] [4].

In his book Thought and Language, Vygotsky argues that a collection of vowels is not a word unless it has meaning. Hence, the meaning is a necessary constitutive feature of the word itself. This means that a word itself and its meaning basically an inclusion. Inclusion is a real and specific action of thought. Hence, thinking and language are closely connected and are difficult to separate [5].

Thinking and language develop and in hand. That the richer the language, the richer the thought, and vice versa, so that thinking enriches language. Words create thought pathways that can be followed. Words are used to speak the language, to direct thinking and to make it more precise.

The language of thinking can contribute significantly to every child and every classroom. However, written and spoken texts in the classroom at all levels use very few thinking words.

The linguistic environment of the school is marked by poor thinking language. Teachers tend to "simplify" their language in order to give their students access to difficult study materials. But these good intentions have prevented pupils from learning the language of thinking which is so necessary for navigating and managing thought [6].

Language is usually a cultural force that can shape tendencies and behavior. This power also applies to the language of thought. The use of thinking language helps in developing thinking dispositions in several ways. It encourages thinking behavior which drives thinking dispositions by instilling strength and inspiration. Not only does thinking language provide information but it also serves as an invitation to embrace and cultivate habits of thinking and helps in developing learners' sensitivity for appropriate opportunities to engage in higher-order thinking [7].

The language of thinking constitutes a significant measure in the learning culture of the classroom. It refers to expressions used in class in order to talk about thinking and to the method through which the language used by the teacher and pupils in class can encourage and develop thinking on a high level.

The language of thinking is composed of daily linguistic expressions relevant to mental procedures and products. To think, to believe, to guess, to hesitate, to doubt, assumption, hypothesis, seeing and conceptualizing are all words comprising a long list of expressions that describe thinking. Such words also make it possible to process information and turn it into knowledge that can be used in different contexts and to exchange knowledge on different subjects [7] [8].

Language includes many ways of describing different types of thinking and many words that describe thinking procedures that are easy to follow. The language of thinking is more than merely a system of tags. It is involved in conceptual development as well. Olson and Astington claim that good thinking requires conceptual ability so that pupils can learn how to adopt beliefs and relate to proverbs [9]. This issue is relevant to the possession of conceptual categories that describe the thinking precision of the thinker himself. For example, to make an assumption versus to hypothesize a hypothesis involves vivid thinking language that provides the thinker with sophisticated meta-cognition. In addition, such language gives the user the ability to understand the literal significance underlying the statements of others [10].

The language of thinking is activated by situations that call for thinking or communication, arbitrated by words and directed toward thinking procedures or products. Thinking language contributes to the management and expression of thinking exactly as the vocabulary of a major field contributes to that field [7].

The more ways a language learner has to describe thinking, the more procedures he has available for actual thinking. The availability of numerous words to describe accurate differences among types of thinking leads to more accurate thinking [8].

In examining the language of thinking, Olson and Astington claim that the advancement towards a higher lev- 
el of thinking depends on the development of richer conceptual categories to think about thinking and to describe thinking [10].

The language of thinking helps in organizing thinking and in describing it more accurately. The words serve as a tool that can be used to think about new information and thoughts. The language of thinking can help teachers assimilate the complex relationship between language, thought and action [11].

Research on children's perceptions of thinking has revealed that the development of such conceptual categories is tied to the growth of a sophisticated network of beliefs regarding the thinking of the thinker himself and of others [12] [13]. Such growth is slow and difficult because it involves the development of a new perception.

The place where we should expect thinking language to be used on a high level is the school classroom. The school is the place where we expect thinking to take place. Generally, teachers use language in order to verbally introduce plans for tasks that pupils have to carry out, and behavioral norms that are acceptable and not acceptable [14]. Language defines a classroom culture defined as the accomplishment of important understandings that are shared by all class members [15]. In effect, the culture "lives inside the language".

The language of thinking helps teachers in the classroom foster a rich linguistic environment in thinking and encourage their pupils to use the language of thinking more fully and more accurately. Such language helps teachers diagnose different thought patterns and thus improve the quality of their pupils' thinking and properly put their meaningful learning potential to use [4].

A widespread objection to the use of rich thinking language is that many pupils, mainly young or weak pupils, do not know the vocabulary or concepts behind words like theory and proof. Never the less, the vocabulary of thinking language incorporates important concepts that help us think. Experience from the teaching of language sin general shows that concepts and vocabulary are best learned in a natural and daily context such as reading or conversation. Therefore, the decision to use rich thinking language in the classroom does not necessarily mean that the pupils must know the exact definitions of sophisticated words in advance.

The current study shows that elementary school pupils already possess the conceptual mechanism required in order to understand the significance of many thinking expressions, even if no one has yet exposed them to this vocabulary [16]. For example, regardless of the fact that pupils in grade four do not know the word "in truth", they are familiar with the conceptual components that constitute the basis for the concept "in truth".

Several studies worldwide point out that expressions of thinking language are sparse in teachers' spoken language. In most instances, teachers use common expressions in order to describe a wide range of situations and precise cognitive activities [10]. Thinking language words are used very sparsely in educational materials.

The Arab education system in Israel is part of the country's general educational system. It is to a large extent run by Jewish functionaries and is defined as an education system for Arabs rather than an Arab education system. Decisions made at the local level by low-level Arab officials are mostly of a technical nature; all significant decisions are made by non-Arab officials, despite the unique national and cultural attributes of the Arab citizens of Israel. This systemic control has made it impossible for the Arabs in Israel to define educational objectives or to shape and direct the Arab education system in accordance with the collective interests of the Arab public, and has prevented any significant involvement of Arab officials (principals and teachers) in the decision-making process within the system [17].

Processes of ongoing and rapid social change taking place within the ranks of Arab society in Israel have led to constant conflict between the desire to preserve the cultural values and traditions of the Arabs and the tendency to open up and embrace modern values. Thus, despite their desire to change and evolve, teachers in the Arab education system, who are themselves the product of the traditional Arab education, preserve what they know and find it difficult to adopt educational perspectives different from those of the teachers who taught them before. Most Arab teachers continue to adopt traditional pedagogical approaches [18].

Obviously, the thinking language used in the classroom, especially in the Arab education system in Israel, is still mainly directed at verbal activity [19]. Such language plays an important role in the pupils' learning process. Thinking language helps pupils think better by enabling them to organize and describe their thoughts in a more intelligent and precise manner. It also conveys messages in support of standards of thought. Teachers who make systematic use of thinking expressions encourage their pupils to think appropriately.

\section{Methods}

\subsection{Study Questions}

The study examined the thinking language of teachers in classrooms in the elementary schools in the Arab edu- 
cation system. This system functions in the midst of a developing community marked by obvious signs of a traditional society. In this society, education is based on four principles: to learn is to listen; to teach is to tell; knowledge is an object; and to be an educated pupil is to know contents with value [20]. Therefore, the study questions are:

1) Is the teachers' language in the elementary schools classrooms marked by a significant amount of thinking language?

2) Is there a difference between lessons based on the subject being taught?

\subsection{Research Sample}

Nineteen teachers from six elementary schools participated in the study. Three teachers from each school participated in the study: one taught Arabic as the mother tongue, a second taught mathematics as an accurate science representative and a third taught Hebrew as a second foreign language. From one school, two teachers of Arabic participated. The choice of the teachers was because of the importance of the three subjects they taught in Arab schools.

\subsection{Research Tools}

The data were collected through structured observation of two lessons for each teacher within one week. Protocols were recorded for all lessons, totaling 38 protocols. A quantitative content analysis was carried out. Statistical testing was performed to examine the variability between teachers based on the subject being taught.

Protocols underwent content analysis, according to Strauss and Corbin: reading the protocols sentence by sentence, searching for categories, defining categories, rereading the protocols, adjusting the categories, and linking categories to determine the final categories [21]. Thinking statements containing language codes were categorized according to the three primary categories: terms indicating epistemic position; terms that describe an intellectual process; and terms that describe the intellectual product [22]. The content analysis was based on the four views of teaching: presentation of information; asking questions; discussing management; organization and management. Analysis of the Qualitative data involved a process of arranging and structuring the collected data in order to interpret and understand it [23].

Interpretation of protocols analysis was carried out on several levels [24]. First, references and statements for each of the dimension were collected from each protocol. After that, consolidated files were gathered. Finally, the contents of a collection of references and statements were analyzed for each dimension to organize them in categories [25].

\section{Findings}

The thinking language of elementary school teachers in the Arab education system in Israel is on a low level. Table 1 shows the distribution of the teachers' statements in percentages according to teaching subject and view of teaching.

The table below shows that the percentage of statements that include thinking language expressions among teachers of Arabic is $18.8 \%$, among teachers of Hebrew is $24.1 \%$ and among math teachers is $37.6 \%$.

Table 1. Distribution of teachers' statements in percentages according to teaching subject and view of teaching.

\begin{tabular}{|c|c|c|c|c|c|c|c|c|}
\hline Teachers & $\begin{array}{c}\text { Teaching } \\
\text { subject }\end{array}$ & Lessons & $\begin{array}{c}\text { Total } \\
\text { statements }\end{array}$ & $\begin{array}{l}\text { Knowledge } \\
\text { presentation }\end{array}$ & $\begin{array}{c}\text { Asking } \\
\text { questions }\end{array}$ & $\begin{array}{c}\text { Discussion } \\
\text { management }\end{array}$ & $\begin{array}{l}\text { Organization } \\
\text { management }\end{array}$ & $\begin{array}{l}\text { Thinking } \\
\text { language }\end{array}$ \\
\hline \multirow{2}{*}{7} & \multirow{2}{*}{ Arabic } & \multirow{2}{*}{14} & 1400 & 634 & 295 & 150 & 321 & 264 \\
\hline & & & $100 \%$ & $45.2 \%$ & $21 \%$ & $10.7 \%$ & $22.9 \%$ & $18.8 \%$ \\
\hline \multirow{2}{*}{6} & \multirow{2}{*}{ Hebrew } & \multirow{2}{*}{12} & 691 & 295 & 174 & 103 & 119 & 167 \\
\hline & & & $100 \%$ & $42.6 \%$ & $25.1 \%$ & $14.9 \%$ & $17.2 \%$ & $24.1 \%$ \\
\hline \multirow[b]{2}{*}{6} & \multirow{2}{*}{ Math } & \multirow{2}{*}{12} & 1042 & 413 & 192 & 197 & 240 & 382 \\
\hline & & & $100 \%$ & $39.6 \%$ & $18.4 \%$ & $18.9 \%$ & $23 \%$ & $36.6 \%$ \\
\hline
\end{tabular}


Table 2 shows that the teaching language of math teachers is richer in thinking expressions than that of the teachers of Arabic and Hebrew. The variability between the group of math teachers and the rest of the groups is significant $(\mathrm{F}=32.287, \mathrm{P}<0.000)$. No significant variability was detected between the teachers of Arabic and those of Hebrew.

\section{Discussion}

The study's findings show that the thinking language of elementary schoolteachers in the Arab education system is poor, ambiguous and general. Similar results were obtained in some developed Western countries [10]. During mathematics lessons, teachers used thinking language more than they did in lessons teaching Arabic or Hebrew. A possible explanation is that the knowledge structure of mathematics obliges the use of words and expressions more relevant to thinking than in Arabic and Hebrew lessons.

The teachers' spoken language is full of ambiguity, general and sometimes misleading. In order to encourage accurate thinking, teachers need to try to lead their pupils toward defined expressions, to be specific in detailing activities, to make accurate comparisons taking suitable features into consideration and to be precise in the language of thinking they use in class.

Table 3 presents the extent of accuracy in the thinking language of teachers in the Arab elementary schools in Israel. The expressions thinking, your opinion and explaining are the kind that may encourage pupils not to think because they are general terms that do not enable the pupils to know how to carry out the required specific skill.

Accordingly, teachers must use cognitive, specific and accurate terminology and show their pupils how to perform the specific skills. For example, instead of saying: "In your opinion, what would happen if...?” they should say: "What do you assume would happen if...?”

In teachers' conversations with pupils regarding class discipline, it also possible to use thinking language that helps pupils decide what behaviors are "acceptable" in the cultural class setting. Instead of giving orders, teachers can pose questions that lead the pupils to examine their behavior and to select more suitable manners. For examples, see Table 4 below.

Observing the different protocols shows that for the most part, teachers give their pupils a great deal of information and prepared answers. Often when a pupil gives the wrong answer to a math problem or incorrectly answers a question, the teacher immediately provides the correct answer or asks another pupil to answer.

Table 2. Inter-group variability by teaching subject.

\begin{tabular}{cccccc}
\hline Measure/variability source & Degrees of freedom & Sum of squares & Mean square & F & Significance level \\
\hline Inter-groups & 2 & 11750.222 & 5875.111 & 32.287 & 0.000 \\
Intra-groups & 35 & 6368.857 & 181.967 & & \\
Total & 37 & 18119.079 & & & \\
\hline
\end{tabular}

Table 3. Examples of thinking language of teachers in theirteaching content (foundand desirable).

\begin{tabular}{|c|c|}
\hline Selected sentences from lessons & It is possible to say \\
\hline What do you think would happen when...? & What do you expect would happen when...? \\
\hline What is your opinion on this story...? & What conclusions can you draw from this story? \\
\hline In your opinion, what would happen if...? & What do assume would happen if...? \\
\hline How do you explain...? & What assumption can you make that explains...? \\
\hline The significance of the new words is... & What should we do when we encounter new words in a specific text...? \\
\hline Question no. 3 is similar to Question no. 1 & What rules or techniques must be used in order to solve problem 3 ? \\
\hline Don't do this & What would happen if you did this? \\
\hline The pupils don't listen to me & These pupils...? Those who do not listen...? \\
\hline These things... & What things exactly...? \\
\hline
\end{tabular}


Table 4. Examples of thinking language of teachers about organizing their teaching (found and desirable).

\begin{tabular}{cr}
\hline Sentences from lessons in the three subjects & It is possible to say \\
Sit down quietly! & $\begin{array}{r}\text { The noise you are making is annoying. Is there another way to speak } \\
\text { without making a disturbance? } \\
\text { Stop interrupting! }\end{array}$ \\
Stop running and sit down in your place! & After the lesson begins, what do pupils need to do? \\
I want all of you to listen. & When the teacher speaks, what must you do?
\end{tabular}

Mathematics teachers generally teach their pupils techniques for solving problems rather than explaining the thoughts behind such techniques. Teachers often focus on the products of thought without considering the thinking process that led to these specific products. The teachers are very quick to give pupils clues and clear instructions to solve problems. Therefore, the pupils carry out the instructions without thinking. Instead, the teachers could ask the specific pupil or the rest of the class to describe the thinking process that led to the incorrect answer. Alternatively they could direct the pupils to the required questions in order to analyze a task, help them identify what is needed to complete it, and then carry it out. This leads them to make decisions independently.

Teachers must be careful not to use ambiguous or inaccurate terms such as:

- General words like always, never, all, everyone, ...

- Ambiguous words like to understand, to evaluate, to know about, ...

- Comparisons like better, cheaper, more useful, ...

- Unlabeled pronouns like they, theirs, we, ...

- Unspecified groups like teachers, parents, things, ...

- Rules that are perceived as clear like need, must, supposed to [8] [26].

Educators who are alert to the cognitive procedures embodied in written and spoken language may help pupils develop awareness of their language and thoughts. Such educators can help pupils assimilate the mutual relations among language, thought and activity [11]. Through question presentation, expression selection, explanation of ideas and procedures, provision of data and refraining from value judgment, teachers may stimulate and encourage thinking among their pupils [14].

Teachers need to use the precise terminology of the language of thinking in order to make such language an inseparable part of the daily discussions in class, to introduce critical questions, to give pupils the opportunity to present data instead of providing solutions, to give instructions that makes sense, to be accurate, to refrain from generalization, to develop meta-cognition, and the like. Teachers must give feedback and positive empowerment to pupils who use thinking language. They must explain the terms and expressions of thinking language directly and clearly [6].

Teachers must help their pupils manage their thinking through the development of meta-cognition; thinking about thinking creates more thinking. When teachers ask their pupils to describe their thinking processes, they learn to think about their thoughts and become more aware of these processes.

For example, when pupils answer questions, teachers must ask them to accurately describe the phases they went through to reach the answer. Or when a pupil indicates that he cannot solve a certain problem, the teacher must not provide him with the correct answer, but rather ask him "What should you do first?" When a pupil states that he prefers one thing to another, the teacher must ask him "What considerations led to this selection?”

How teachers deal with pupils wrong answers?

Found: immediate rejection while ignoring, the teacher's constant striving for the right answer without checking the reasons of the pupil's mistakes.

Desirable: the teacher chooses not to respond at this stage in order to give the pupil to cope with the problem himself.

Found: the teacher providing the Answer, mainly providing specific guidance on the way to resolution, providing recipe.

Desirable: guidance of students finding their cognitive mistake and help them get the right answer.

\section{Conclusions}

In summary, one may say that the teaching language of elementary school teachers in the Arab education system 
in Israel uses general and ambiguous words, is quite broad and self-explanatory, and uses unlabeled pronouns in non-detailed groups. The teachers' language of thinking is scanty and nonsystematic.

This pioneering study constitutes initial research on the subject of thinking in the Arab education system in Israel. Additional studies are recommended using a more representative sample and in secondary schools. Studies are needed that introduce suitable solutions in order to develop thinking language and make it part of the classroom climate and organizational culture in the educational institutions.

Views must be expressed regarding teacher training and continuing education. Teacher educators must also be trained in the topic of thinking in order to be able to enrich the thinking language in the teacher training colleges and to develop such language among the trainees, whether indirectly or through regular courses dedicated to this topic. Training programs should provide teacher trainees with experiential learning experiences towards understanding and developing thinking. As a result, they will be able to develop the language of thinking among pupils as an important means of transition from learning that focuses on memorizing information towards learning for understanding and the development of thinking. Responsible individuals at the colleges of education must take the language of thinking into consideration and encourage research and initiatives on this topic.

\section{References}

[1] McKinsey Report (2007) How the World's Best-Performing School Systems Come out on Top. http://alamin99.wordpress.com/2008/02/22/mckinsey-report/

[2] Carmon, A., et al. (2006) The Third Approach and Organization of Knowledge: A Strategy for Teacher Training Fosters Thinking. Mofet Institute, Tel-Aviv. (In Hebrew)

[3] Perkins, D. (1986) Knowledge as Design: Teaching Thinking through Content. In: Baron, J. and Sternberg, R., Eds., Teaching Thinking Skills: Theory and Practice, Freeman \& Company, New York.

[4] Weinberger, J. and Zohar, P. (2005) Development of Thinking-Challenge in Teacher Education. Mofet Institute, Tel Aviv. (In Hebrew)

[5] Vygotsky, L. (2007) Thought and Speech. In: Kotik-Friedgut, B., Ed., Chapter Seven: Thought and Word, Magnes Press, Jerusalem, 254-309.

[6] Abu-Hussain, J. (2001) Thinking Culture in the Arab Educational Institutes in Israel. Jame’a, 5, 23-35. (In Hebrew)

[7] Perkins, D., et al. (2000) Landscapes of the Mind: Article on Education toward Good Thinking. In: Harpaz, Y., Ed., Branco Weiss Institute, Jerusalem. (In Hebrew)

[8] Tishman, S., et al. (1996) The Thinking Class: Learning and Teaching in a Thinking Culture. Branco Weiss Institute, Jerusalem. (In Hebrew)

[9] Olson, D.R. and Astington, J.W. (1991) Talking about Text: How Literacy Contributes to Thought. Journal of Pragmatics, 14, 705-721. http://dx.doi.org/10.1016/0378-2166(90)90002-U

[10] Olson, D.R. and Astington, J.W. (1993) Thinking about Thinking: Learning How to Take Statements and Hold Beliefs. Educational Psychologist, 28, 7-24. http://dx.doi.org/10.1207/s15326985ep2801_2

[11] Marzano, R. and Hutchins, C.L. (1985) Thinking Skills: A Conceptual Framework. Mid-Continent Regional Educational Laboratory, Aurora.

[12] Leslie, A.M. (1988) Some Implications of Pretense for Mechanisms Underlying the Child's Theory of Mind. In: Astington, J.W., Harris, P.L. and Olson, D.R., Eds., Developing Theories of Mind, Cambridge University Press, Cambridge.

[13] Wellman, H. (1990) The Child's Theory of Mind. MIT Press, Cambridge.

[14] Costa, A.L. and Marzano, R. (1991) Teaching the Language of Thinking. In: Costa, A.L., Ed., Developing Minds: A Resource Book for Teaching, ASCD, Alexandria.

[15] Purkey, S.C. and Smith, M.S. (1982) Effective Schools: A Review. Wisconsin Center for Educational Research, University of Wisconsin, Madison.

[16] Astington, J.W. and Olson, D.R. (1990) Metacognitive and Metalinguisztic Language: Learning to Talk about Thought. Applied Psychology, 39, 77-87. http://dx.doi.org/10.1111/j.1464-0597.1990.tb01038.x

[17] Jabarin, Y. and Agbariyya, A. (2010) Education in Waiting: Government Policy and Civil Initiatives for the Promotion of Arab Education in Israel. Dirasat, Haifa. (In Hebrew)

[18] Abu-Hussain, J. and Essawi, M. (2014) School Principals’ Perceptions of Teacher Evaluation in the Arab Education System in Israel. Journal of Education and Training Studies, 2, 31-43. http://dx.doi.org/10.11114/jets.v2i2.255

[19] Abu-Hussain, J. and Gonen, S. (2013) Education for Responsibility and Responsibility for Education. Mofet Institute 
and Al-Qasemi College of Education, Tel-Aviv. (In Hebrew)

[20] Harpaz, Y. (2000) Towards Teaching and Learning in a Thinking Community. Hennukh Hahashiva (Thinking Education), 18, 6-31. (In Hebrew)

[21] Strauss, A. and Corbin, J. (1990) Basics of Qualitative Research. Sage, Newbury Park.

[22] Tishman, S. and Perkins, D. (1997) Language of Though: In Education Thinking—1997 Newsletters. Newsletter No. 11, Branco Weiss Institute, Jerusalem, 21-28. (In Hebrew)

[23] Shkedi, A. (2004) Words of Meaning: Qualitative Research—Theory and Practice. Ramot Publishers, Tel Aviv University, Tel Aviv. (In Hebrew)

[24] Gertz, C. (1990) Interpretations of Cultures. Keter, Jerusalem. (In Hebrew)

[25] Guba. E.G. and Lincoln. Y.S., Eds. (1981) Hand Book of Qualitative Research. London, 105-117.

[26] Laborde, G. (1984) Influencing with Integrity. Syntony Press, Palo Alto. 